\title{
Disease and Economic Burden of Hospitalizations Attributable to Diabetes Mellitus and Its Complications: A Nationwide Study in Brazil
}

\author{
Michelle Quarti Machado Rosa ${ }^{1, *(\mathbb{D})}$, Roger dos Santos Rosa ${ }^{2}$ (D), Marcelo G. Correia ${ }^{3}$, \\ Denizar V. Araujo ${ }^{1}$ (D), Luciana R. Bahia ${ }^{1}$ and Cristiana M. Toscano ${ }^{4}$ (DD \\ 1 Internal Medicine Department, State University of Rio de Janeiro, Rio de Janeiro 20551-030, Brazil; \\ denizarvianna@gmail.com (D.V.A.); lucianabahia@gmail.com (L.R.B.) \\ 2 Social Medicine Department, School of Medicine, Federal University of Rio Grande do Sul, \\ Porto Alegre 90035-003, Brazil; roger.srosa@gmail.com \\ 3 Biostatistics and Bioinformatics Department, National Institute of Cardiology, Rio de Janeiro 22240-006, \\ Brazil; mgoulart.inc@gmail.com \\ 4 Collective Health Department, Federal University of Goiás, Goiânia 75345-000, Brazil; ctoscano@terra.com.br \\ * Correspondence: michelleqmrosa@gmail.com; Tel.: +55-1-(929)-255-2923
}

Received: 16 November 2017; Accepted: 1 February 2018; Published: 8 February 2018

\begin{abstract}
Diabetes is associated with a significant burden globally. The costs of diabetes-related hospitalizations are unknown in most developing countries. The aim of this study was to estimate the total number and economic burden of hospitalizations attributable to diabetes mellitus (DM) and its complications in adults from the perspective of the Brazilian Public Health System in 2014. Data sources included the National Health Survey (NHS) and National database of Hospitalizations (SIH). We considered diabetes, its microvascular (retinopathy, nephropathy, and neuropathy) and macrovascular complications (coronary heart disease, cerebrovascular disease, and peripheral arterial disease), respiratory and urinary tract infections, as well as selected cancers. Assuming that DM patients are hospitalized for these conditions more frequently that non-DM individuals, we estimated the etiological fraction of each condition related to DM, using the attributable risk methodology. We present number, average cost per case, and overall costs of hospitalizations attributable to DM in Brazil in 2014, stratified by condition, state of the country, gender and age group. In 2014, a total of 313,273 hospitalizations due to diabetes in adults were reported in Brazil (4.6\% of total adult hospitalization), totaling (international dollar) Int $\$ 264.9$ million. The average cost of an adult hospitalization due to diabetes was Int $\$ 845,19 \%$ higher than hospitalization without DM. Hospitalizations due to cardiovascular diseases related to diabetes accounted for the higher proportion of costs $(47.9 \%)$, followed by microvascular complications (25.4\%) and DM per se $(18.1 \%)$. Understanding the costs of diabetes and its major complications is crucial to raise awareness and to support the decision-making process on policy implementation, also allowing the assessment of prevention and control strategies.
\end{abstract}

Keywords: diabetes mellitus; cost and cost analysis; hospitalization; inpatients; health care expenditure; cardiovascular disease; chronic non-communicable disease

\section{Introduction}

Non-communicable diseases (NCD) are the leading cause of disability and mortality globally, being responsible for 39.5 million deaths in 2015 [1]. Diabetes mellitus (DM) is one of the four major NCDs, together with cardiovascular diseases, cancer, and chronic respiratory diseases [2]. Diabetes prevalence is rising, representing a growing challenge to public health. A total of 415 million people 
were estimated to be diagnosed with diabetes worldwide in 2015, and it is expected that this number will rise to 642 million by 2040 [3]. One study demonstrated worldwide prevalence trends increasing from 4.3 to $9.0 \%$ in men, and from 5.0 to $7.9 \%$ in women from 1980 to 2014 , with steeper increase in low and middle-income countries [4]. Brazil ranks fourth in the world in number of individuals with diabetes [4]. The 2013 Brazilian National Health Survey (NHS) demonstrated self-reported prevalence of diabetes of $6.2 \%$ in the population aged 18 years or older, reaching $19.9 \%$ in those aged 65-74 years [5]. This prevalence is certainly underestimated given other previous Brazilian studies with laboratory confirmation, which have shown that approximately half of individuals with diabetes were unaware of the diagnosis $[6,7]$.

Studies have demonstrated that people with diabetes are at higher risk of hospitalization [8-11] and readmission than people without diabetes $[12,13]$. The diabetes economic burden is significant and is expected to increase over time. Global health expenditures related to diabetes and its complications were estimated at $\$ 673$ billion in 2015 [3]. Such costs represent a significant portion of national health expenditures, varying from 2.5 to $15 \%$ by country, depending on availability and access to healthcare services [14].

In the early 2000s, Brazil initiated a series of strategies aiming at increasing access of the population with diabetes and hypertension to healthcare services [15] and providing early diagnosis for diabetes through a national population-based screening program [16,17]. Later, a National Strategic Plan for chronic NCD was developed and implemented [18]. This plan, in accordance to the World Bank and the International Diabetes Federation, recommends countries conduct national studies of cost of illness and economic burden of diabetes [3].

Healthcare in Brazil is provided by both public and private sectors. Public healthcare services are provided by the National Unified Health System (SUS), which offers, free of charge, universal health access covering about $75 \%$ of the population in the country [19].

Demographic, epidemiological and nutritional transition processes, urbanization and economic and social growth contribute to the greater risk of developing chronic NCD. Diabetes, stroke, myocardial infarction, hypertension, cancer and chronic respiratory diseases account for about $80 \%$ of deaths in Brazil, reaching heavily poor sections of the population and more vulnerable groups, such as the population with low schooling and income [18].

The full economic burden of diabetes in Brazil is still unknown. Hospitalization costs associated with diabetes and its complications are reported to be the most significant portion of direct medical costs. In this study, we estimated the number of hospitalizations due to DM and its complications and their economic burden in Brazil.

\section{Materials and Methods}

\subsection{Study Design, Site and Population}

We estimated the number of hospitalization due to DM and its complications in 2014 in Brazil, as well as its costs. We considered hospitalizations occurring in adults aged 20 years and older in all 27 states in the country, through SUS.

\subsection{Ethics Approval}

The Ethics Committee of Federal University of Goias in Goiania, Brazil, granted ethical approval for this investigation in October 2014 (\# 852808). Considering we used secondary publicly available data, with no personal identifiers, the Institutional Research Board (IRB) waived written individual consent. 


\subsection{Data Sources}

\subsubsection{Diabetes Prevalence}

The prevalence of self-reported diabetes was obtained from the 2013 NHS [5], stratified by gender, age groups and state within the country. The original NHS database was analyzed and estimates of self-reported diabetes prevalence were generated considering a positive response of surveyed individuals to question Q030 “Has any doctor ever given a diagnosis of diabetes?", excluding individuals reporting diagnosis of gestational DM (as responded in a different question of the survey). Evidence suggests that self-report of a physician's diagnosis of diabetes is a good estimate of diagnosed diabetes [20].

As individuals with diabetes who are unaware of the disease may also be hospitalized due to diabetes or its complications, we considered the prevalence of undiagnosed diabetes for this study. To account for undiagnosed diabetes, the prevalence of self-reported diabetes was multiplied by a factor of 2, based on recent evidence from the Brazilian literature, indicating that half of the individuals with diabetes diagnosis by laboratory confirmation were unaware of their disease [7]. This strategy has been applied by other authors for the estimation of diabetes disease burden [21].

\subsubsection{Hospitalization and Cost Data}

All hospitalizations occurring nationwide in SUS are recorded in a National Hospitalization Information System (SIH), which includes information on hospital admissions and discharges and its costs to the SUS. We obtained raw hospitalization data from SIH-SUS, without personal identification information, which are publicly available online [22].

A standardized hospital admission form (AIH) reports the main hospitalization diagnosis. We considered two types of AIH: AIH-1 (conventional hospitalization authorization) for the estimates of diabetes hospitalizations, and AIH-5 (long-term hospitalization authorization) considered in addition to AIH-1 for economic burden estimates.

International statistical classification of diseases and related health problems, 10th revision (ICD10) codes [23] assigned for admission diagnoses of all hospitalized patients are recorded in the SIH. The databases were extracted in October/2016, and the following variables were considered: type of $\mathrm{AIH}$, state of residence, sex, age group, date of admission, admission diagnosis, and cost of hospitalization. The data were extracted and analyzed in Microsoft Excel ${ }^{(R)}$ Office Excel (R) 2007 (12.0.4518.1014) MSO (12.0.4518.1014) spreadsheets.

\subsubsection{Population Data}

Considering 2014 as the base year for this cost analysis, population estimates for 2014, by age group, and gender for each state were obtained from the National Institute of Geography and Statistics. The total adult population (20 years and older) in 2014 was estimated at 137,640,060 inhabitants [24]. The age groups were divided in 5-year strata from the age of 20. Standardized hospitalization rates adjusted by gender and age group were calculated using direct standardization method.

\subsection{Outcomes of Interest}

We considered hospitalizations due to diabetes and its complications. Complications included microvascular (retinopathy, nephropathy, and neuropathy), macrovascular (coronary heart disease, cerebrovascular disease, and peripheral arterial disease), respiratory and urinary tract infections, as well as selected cancers. Hospitalizations for DM in pregnancy (ICD-10 O24) were excluded.

Hospitalizations were thus categorized into two groups: (1) those in which the main diagnosis was reported as diabetes and coded as ICD10 E10 to E14; (2) those in which the main diagnosis was reported as any chronic complication of DM and related diseases, including infectious and neoplastic diseases for which DM is considered to be an important risk factor. The list of diagnosis included in this second group was adapted from the one considered by the American Diabetes Association's study 
of economic costs of diabetes in the US [25], and included 66 diagnosis as coded by ICD-10 three-digit codes (Supplementary Table S1).

\subsection{Relative Risks}

For each and all chronic complications of DM and related conditions considered, we obtained individual relative risks of hospitalization for people with diabetes compared to those without the disease. Relative risk estimates for each diagnosis were obtained through systematic literature reviews (Supplementary Table S1).

\subsection{Data Analysis}

\subsubsection{Burden of Hospitalizations Attributed to Diabetes and Its Complications}

Except for hospitalizations in which the main diagnosis was reported as DM, the proportion of hospitalizations due to DM was estimated using the attributable risk methodology. This method considers that diabetic patients use healthcare services more than non-diabetics and that a portion of the care associated with such medical care can be attributed to diabetes. The risk of presenting a particular medical condition, according to the presence or absence of DM, and the proportion of the population with the disease are combined to calculate the etiological fraction.

The etiological fraction for each of the 66 conditions considered were calculated using the following formula:

$$
\mathrm{RAPI}=[\mathrm{P} \times(\mathrm{iRR}-1)] /[\mathrm{P} \times(\mathrm{iRR}-1)+1],
$$

where RAPI is the fraction of risk attributable to the population for the medical condition " $\mathrm{i}$ " due to diabetes, $P$ represents the prevalence rate of diabetes in each state by gender and age group, and iRR is the relative risk of hospitalization for people with diabetes compared to those without the disease.

A total of 702 demographic strata were generated, resulting from a combination of 2 sex categories, 13 age categories (i.e., 20-24, 25-29, 30-34, 35-39, 40-44, 45-49, 50-54, 55-59, 60-64, 65-69, 70-74, 75-79 and 80+ years), and 27 states. The number of hospitalizations for each of the conditions considered, by each of these 702 demographic strata (sex, age group, and state) was obtained.

Specific etiological fractions were then applied to the number of hospitalizations obtained for each of the 702 demographic strata, resulting in 46,332 estimates (66 ICD-10 codes multiplied by 702 demographic strata) of the proportion of hospitalizations attributable to DM.

Results were further grouped in four age groups (20-44, 45-64, 65-74 and 75+ years old), and are reported by sex, age group and main diagnosis. Diagnosis groups considered for reporting results are DM, cardiovascular disease, kidney disease, eye disease, neurological disease, infectious disease, and neoplasms.

Proportion of hospitalization and population hospitalization rates (per 10,000 population aged 20 years and older) are reported, comparing overall hospitalizations and those due to diabetes.

\subsubsection{Direct Medical Costs Attributed to Diabetes and Its Complications}

Economic burden analysis considered the SUS perspective as payer. A top-down costing methodology was used considering on the combination of prevalence and relative risks [26]. This methodology allocates to diabetes a portion of the total expenditures of hospitalizations (for several conditions) that could be due to the diabetes, based on the estimate of the proportion of total services consumed by individuals with the disease $[27,28]$ as described above.

Hospitalization charges are based on Diagnostic Related Groups (DRG), with addition of values resulting from on intensive care unit (ICU) stay, certain special medications, prostheses and other selected materials. In addition to these direct medical costs, which include hospital stay, staff, diagnostic and therapeutic procedures, materials and drugs, non-medical costs for hospital stay of a parent or caregiver accompanying the hospitalized individual is also included. Reimbursed values by cost items are standardized nationwide based on SUS own price list [29]. 
Monetary values were obtained in Brazilian reais $(R \$)$ and then converted to international dollars (Int\$) considering the purchasing power parity (PPP) (conversion factor 1.748) [30].

Total hospitalization costs and average cost per hospitalization, by diagnostic groups, and by specific hospitalization cause are presented, comparing all hospitalizations and those attributed to diabetes. Costs are further presented stratified by gender and age group.

\section{Results}

We considered the national prevalence of undiagnosed diabetes as $12.4 \%$, varying by age group and state (Supplementary Table S2). As such, we estimated that 17,320,339 adult individuals in the country would have diabetes.

A total of 11.3 million hospitalizations were registered in 2014 in the SIH/SUS, of which $8,629,004$ million $(76.2 \%)$ were adults ( 20 or more years). Of these adult hospitalizations, 284,675 received an authorization for prolonged stay (AIH-5).

In 2014, an estimated 313,273 hospitalizations due to diabetes occurred in Brazil, corresponding to $3.6 \%$ of total hospitalizations and representing a hospitalization rate of 22.8/10,000 adults. Excluding hospitalizations for pregnancy, childbirth and the puerperium, hospitalizations attributable to diabetes represent $4.6 \%$ of total adult hospitalization in Brazil in 2014.

Among these, DM per se (ICD-10 codes E10-E14) accounted for $41.9 \%$ of hospitalizations, followed by cardiovascular diseases attributable to diabetes (26.5\%) (Table 1). The population hospitalization rates increased from 3.5 and 3.8/10,000 adults for men and women, respectively, aged 20-44 years to 146.0 and 133.3 for the age group of 75 and over. Women were hospitalized more than men when considering both absolute number and crude hospitalization rate. However, when considering age-standardized rates, these are higher for men (23.9/10,000 population) when compared to women (21.9/10,000 population). While the average cost of a hospitalization of an adult individual was Int $\$ 709$ in 2014, the average cost of a hospitalization due to diabetes and related diseases was $19 \%$ higher, reaching Int $\$ 845$. Among the hospitalizations due to diabetes, hospitalizations due to kidney (Int\$1602) and cardiovascular (Int\$1529) diseases were the ones with higher average cost, and hospitalizations due to diabetes had the lower average cost (Int\$364). Average hospitalization cost was significantly higher in men in all age groups and for all diagnosis groups, except for selected neoplasms, probably because of breast cancer costs included in this group (Table 2).

Total costs for adult hospitalization in the SUS in 2014 were approximately Int $\$ 6.1$ billion. Admissions due to diabetes and related conditions reached Int $\$ 264.9$ million, representing 4.3\% of total hospitalization costs. After excluding hospitalizations for pregnancy, childbirth and the puerperium, this proportion increased to $4.8 \%$. Diabetes mellitus per se accounted for only $18.1 \%$ of total costs attributable to hospitalization due to diabetes and related conditions, with cardiovascular diseases attributable to diabetes $(47.9 \%)$ accounting for the higher proportion of overall costs. Total hospitalization costs were significantly higher in men from 20-74 years. The reverse was observed in the age group of 75 years and older (Table 3 ).

Among the hospitalizations with the main diagnosis reported as DM, the number of hospitalizations (52.5\%), and total costs (46.2\%) related to unspecified DM ICD-10 code E14) were the most observed, despite presenting the lower average hospitalization cost. The second most relevant cause of hospitalization in this group was insulin-dependent hospitalizations (ICD-10 E10), with the higher average hospitalization cost (Table 4).

Cardiovascular diseases due to diabetes accounted for $13.1 \%(n=82,958)$ of admissions and $14.3 \%$ (Int $\$ 126,849,817$ ) of costs of all hospitalizations for cardiovascular diseases in SUS. In hospitalizations due to diabetes, average hospitalization costs due to cardiovascular disease were $10.4 \%$ higher than non-diabetes hospitalizations. Among all hospitalizations due to cerebral infarction (ICD-10 code I63) and transient ischemic stroke and related syndromes (ICD-10 code G45), 25\% of hospitalizations and costs could be attributed to diabetes (Table 5). 
Microvascular diseases due to diabetes (kidney, eye and neurologic diseases) accounted for a greater share of total hospitalizations (29.1\%) and associated costs $(24.5 \%)$. Of worth noting is the high number of hospitalization and overall costs with diabetes hospitalization due to renal diseases, in particular due to chronic kidney disease (ICD-10 code N18) (Table 6).

Hospitalizations for respiratory and urinary infections, for which diabetes was considered a risk factor, represent a small percentage $(5.3 \%)$ when compared to the cardiovascular $(13.1 \%)$ and microvascular (29.1\%) groups in relation to total SUS and accounted for $6.5 \%$ of hospitalizations due to DM. Even so, this percentage was reached due to the large participation of respiratory infections (96.5\%) in this group, with emphasis on pneumonia per unspecified organism (ICD-10 J18) (69.9\%) (Table 7).

Hospitalizations for neoplastic diseases have a small participation (7.3\%) of total hospitalizations in comparison with other groups and represent $2.7 \%$ of hospitalizations due to DM. Breast cancer $(4.0 \%)$ and colorectal cancer (5.8\%) admissions were among those with the lowest values, while cancers of endometrium $(20.0 \%)$, pancreas $(18.6 \%)$ and liver and intrahepatic bile ducts $(22.6 \%)$ were among those with the highest values (Table 8). 
Table 1. Number and rates of hospitalization due to diabetes and related conditions, by age-group and sex, Unified Health System (SUS), Brazil, 2014.

\begin{tabular}{|c|c|c|c|c|c|c|c|c|c|c|c|}
\hline \multirow{4}{*}{ Diabetes and Related Conditions } & \multicolumn{8}{|c|}{ Age Groups (Years) } & & & \\
\hline & \multicolumn{2}{|c|}{$20-44$} & \multicolumn{2}{|c|}{$45-64$} & \multicolumn{2}{|c|}{$65-74$} & \multicolumn{2}{|c|}{$75+$} & \multicolumn{3}{|c|}{ Total } \\
\hline & \multicolumn{2}{|c|}{ (n) } & \multicolumn{2}{|c|}{ (n) } & \multicolumn{2}{|c|}{ (n) } & \multicolumn{2}{|c|}{ (n) } & \multicolumn{3}{|c|}{ (n) } \\
\hline & Men & Women & Men & Women & Men & Women & Men & Women & Men & Women & All \\
\hline $\begin{array}{l}\text { Diabetes Mellitus } \\
\text { Attributed to diabetes }\end{array}$ & 8898 & 10,243 & 25,991 & 27,141 & 14,014 & 17,689 & 10,465 & 16,931 & 59,368 & 72,004 & 131,372 \\
\hline Cardiovascular Disease * & 1588 & 1683 & 14,527 & 12,046 & 14,482 & 13,536 & 10,683 & 14,412 & 41,281 & 41,678 & 82,958 \\
\hline Kidney Disease & 1017 & 1170 & 4066 & 3385 & 3750 & 2844 & 3475 & 2852 & 12,308 & 10,251 & 22,559 \\
\hline Eye Disease & 315 & 216 & 2417 & 2885 & 3400 & 5326 & 2333 & 3922 & 8465 & 12,349 & 20,814 \\
\hline Neurological Disease ** & 1668 & 976 & 6200 & 4561 & 4165 & 3268 & 2820 & 3050 & 14,853 & 11,855 & 26,708 \\
\hline Infectious Disease *** & 564 & 685 & 1847 & 1866 & 2547 & 2614 & 4405 & 5846 & 9362 & 11,011 & 20,373 \\
\hline Neoplasms **** & 104 & 439 & 1105 & 2332 & 1016 & 1865 & 542 & 1085 & 2767 & 5721 & 8488 \\
\hline Total $* * * * *$ & 14,154 & 15,412 & 56,154 & 54,217 & 43,374 & 47,142 & 34,723 & 48,098 & 148,404 & 164,869 & 313,273 \\
\hline $\begin{array}{l}\text { Crude Rate/10,000 population } \\
\text { Age adjusted Rate/10,000 population }\end{array}$ & 3.5 & 3.8 & 28.4 & 25.4 & 101.6 & 90.1 & 146.0 & 133.3 & $\begin{array}{l}22.2 \\
23.9\end{array}$ & $\begin{array}{l}23.3 \\
21.9\end{array}$ & 22.8 \\
\hline
\end{tabular}

* Coronary heart disease and cerebrovascular disease; ${ }^{* *}$ Diagnoses related to diabetic neuropathy; ${ }^{* * *}$ Urinary and respiratory infections; ${ }^{* * * *}$ Breast, endometrial, pancreas, colorectal, hepatocarcinoma, cholangiocarcinoma. ${ }^{* * * * *}$ Numbers do not necessarily sum to totals because of rounding.

Table 2. Average hospitalization cost (Int\$) due to diabetes and related conditions by age-group and sex, SUS, Brazil, 2014

\begin{tabular}{|c|c|c|c|c|c|c|c|c|c|c|c|}
\hline \multirow{4}{*}{ Diabetes and Related Conditions } & \multicolumn{8}{|c|}{ Age Groups (Years) } & & & \\
\hline & \multicolumn{2}{|c|}{$20-44$} & \multicolumn{2}{|c|}{$45-64$} & \multicolumn{2}{|c|}{$65-74$} & \multicolumn{2}{|c|}{$75+$} & \multicolumn{3}{|c|}{ Total } \\
\hline & \multirow[b]{2}{*}{ Men } & \multirow[b]{2}{*}{ Women } & \multirow[b]{2}{*}{ Men } & \multirow[b]{2}{*}{ Women } & \multirow[b]{2}{*}{ Men } & \multirow[b]{2}{*}{ Women } & \multirow[b]{2}{*}{ Men } & \multirow[b]{2}{*}{ Women } & \multicolumn{3}{|c|}{ (Int\$) } \\
\hline & & & & & & & & & Men & Women & All \\
\hline $\begin{array}{c}\text { Diabetes Mellitus } \\
\text { Attributed to diabetes }\end{array}$ & 551 & 516 & 355 & 319 & 360 & 321 & 340 & 324 & 383 & 349 & 364 \\
\hline Cardiovascular Disease * & 1245 & 916 & 1960 & 1469 & 1908 & 1478 & 1364 & 1036 & 1760 & 1300 & 1529 \\
\hline Kidney Disease & 3393 & 2543 & 2292 & 1909 & 1400 & 1189 & 823 & 853 & 1696 & 1488 & 1602 \\
\hline Eye Disease & 1324 & 1206 & 917 & 750 & 627 & 525 & 497 & 455 & 700 & 567 & 621 \\
\hline Neurological Disease ** & 545 & 486 & 653 & 595 & 745 & 691 & 807 & 769 & 696 & 657 & 679 \\
\hline Infectious Disease *** & 578 & 435 & 669 & 607 & 681 & 635 & 615 & 620 & 642 & 610 & 624 \\
\hline Neoplasms ${ }^{* * * *}$ & 1054 & 1146 & 1135 & 1214 & 1250 & 1230 & 1233 & 1214 & 1194 & 1214 & 1207 \\
\hline Total ***** & 855 & 736 & 994 & 768 & 1065 & 808 & 801 & 664 & 956 & 746 & 845 \\
\hline
\end{tabular}

* Coronary heart disease and cerebrovascular disease; ${ }^{* *}$ Diagnoses related to diabetic neuropathy; *** Urinary and respiratory infections; ${ }^{* * *}$ Breast, endometrial, pancreas, colorectal, hepatocarcinoma, cholangiocarcinoma. ${ }^{* * * * *}$ Numbers do not necessarily sum to totals because of rounding. 
Table 3. Total hospitalization cost (in 000 Int\$) due to diabetes and related conditions by age group and sex, SUS, Brazil, 2014.

\begin{tabular}{|c|c|c|c|c|c|c|c|c|c|c|c|}
\hline \multirow{3}{*}{ Diabetes and Related Conditions } & \multicolumn{8}{|c|}{ Age Groups (Years) } & & & \\
\hline & \multicolumn{2}{|c|}{$20-44$} & \multicolumn{2}{|c|}{$45-64$} & \multicolumn{2}{|c|}{$65-74$} & \multicolumn{2}{|c|}{$75+$} & \multicolumn{3}{|c|}{ Total } \\
\hline & Men & Women & Men & Women & Men & Women & Men & Women & Men & Women & All \\
\hline $\begin{array}{c}\text { Diabetes Mellitus } \\
\text { Attributed to diabetes }\end{array}$ & 4906.8 & 5287.7 & 9231.7 & 8650.5 & 5050.5 & 5684.6 & 3559.1 & 5489.5 & $22,747.9$ & $25,112.4$ & $47,860.3$ \\
\hline Cardiovascular Disease * & 1977.4 & 1540.9 & $28,480.1$ & $17,698.6$ & $27,636.5$ & $20,006.1$ & $14,573.2$ & $14,934.9$ & $72,667.3$ & $54,180.5$ & $126,847.8$ \\
\hline Kidney Disease & 3449.4 & 2975.7 & 9320.8 & 6461.9 & 5250.6 & 3380.8 & 2859.6 & 2432.4 & $20,880.3$ & $15,250.9$ & $36,131.2$ \\
\hline Eye Disease & 416.9 & 260.7 & 2217.3 & 2162.8 & 2133.3 & 2798.2 & 1159.3 & 1782.6 & 5926.8 & 7004.3 & $12,931.1$ \\
\hline Neurological Disease ${ }^{* *}$ & 909.6 & 475.0 & 4049.4 & 2713.4 & 3101.1 & 2258.1 & 2276.1 & 2346.6 & $10,336.2$ & 7793.1 & $18,129.3$ \\
\hline Infectious Disease $* * *$ & 325.6 & 298.0 & 1236.4 & 1132.6 & 1734.8 & 1660.2 & 2709.9 & 3624.1 & 6006.7 & 6714.9 & $12,721.6$ \\
\hline Neoplasms **** & 109.7 & 502.4 & 1254.6 & 2831.1 & 1270.1 & 2292.8 & 668.2 & 1317.9 & 3302.4 & 6944.2 & $10,246.6$ \\
\hline Total ***** & $12,095.4$ & $11,340.6$ & $55,790.3$ & $41,650.9$ & $46,176.9$ & $38,080.8$ & $27,805.4$ & 31,928 & $141,867.8$ & $123,000.3$ & $264,867.9$ \\
\hline
\end{tabular}

* Coronary heart disease and cerebrovascular disease; ${ }^{* *}$ Diagnoses related to diabetic neuropathy; ${ }^{* * *}$ Urinary and respiratory infections; ${ }^{* * * *}$ Breast, endometrial, pancreas, colorectal, hepatocarcinoma, cholangiocarcinoma. ${ }^{* * * * *}$ Numbers do not necessarily sum to totals because of rounding.

Table 4. Number, average and total hospitalization cost due to diabetes (E10-E14), adults (20+ years), SUS, Brazil, 2014.

\begin{tabular}{|c|c|c|c|}
\hline Diabetes Codes & Number & Average Hospitalization Cost & Total Hospitalization Cost \\
\hline & (n) & (Int\$) & (in 000 Int\$) \\
\hline E10 Insulin-dependent diabetes mellitus & 38,883 & 452.62 & $17,599.3$ \\
\hline E11 Non-insulin-dependent diabetes mellitus & 12,707 & 340.82 & 4330.7 \\
\hline E12 Malnutrition-related diabetes mellitus & 1454 & 384.83 & 559.5 \\
\hline E13 Other specified diabetes mellitus & 9341 & 349.68 & 3266.4 \\
\hline E14 Unspecified diabetes mellitus & 68,987 & 320.41 & $22,104.3$ \\
\hline Total Diabetes (E10-E14) * & 131,372 & 364.31 & $47,860.2$ \\
\hline
\end{tabular}

* Numbers do not necessarily sum to totals because of rounding. 
Table 5. Number, average and total hospitalization cost due to cardiovascular disease, overall and related to diabetes, adults (20+ years), SUS, Brazil, 2014.

\begin{tabular}{|c|c|c|c|c|c|c|}
\hline \multirow[b]{2}{*}{ Diabetes and Related Conditions } & \multicolumn{3}{|c|}{ Overall Hospitalization } & \multicolumn{3}{|c|}{ Hospitalization Due to Diabetes } \\
\hline & Number & $\begin{array}{c}\text { Average } \\
\text { Hospitalization Cost }\end{array}$ & $\begin{array}{c}\text { Total } \\
\text { Hospitalization Cost }\end{array}$ & Number & $\begin{array}{c}\text { Average } \\
\text { Hospitalization Cost }\end{array}$ & $\begin{array}{c}\text { Total } \\
\text { Hospitalization Cost }\end{array}$ \\
\hline & (n) & (Int\$) & (in 000 Int\$) & (n) & (Int\$) & (in 000 Int\$) \\
\hline I20 Angina pectoris & 123,897 & 2265.29 & $280,662.5$ & 21,202 & 2318.49 & $49,156.1$ \\
\hline I21 Acute myocardial infarction & 91,951 & 2025.70 & $186,265.3$ & 13,784 & 2036.35 & $28,070.1$ \\
\hline $\begin{array}{l}\text { I23 Certain current complications } \\
\text { following acute myocardial infarction }\end{array}$ & 937 & 2069.76 & 1939.4 & 137 & 2293.55 & 315.1 \\
\hline I24 Other acute ischemic heart diseases & 19,283 & 2878.38 & $55,503.8$ & 3005 & 3009.33 & 9041.7 \\
\hline I22 Subsequent myocardial infarction & 2248 & 1669.43 & 3752.9 & 340 & 1720.45 & 584.4 \\
\hline I25 Chronic ischemic heart disease & 14,856 & 4065.16 & $60,392.1$ & 2712 & 4065.62 & $11,027.9$ \\
\hline I10 Essential (primary) hypertension & 74,141 & 202.77 & $15,033.7$ & 10,075 & 228.94 & 2306.6 \\
\hline I11 Hypertensive heart disease & 9704 & 244.19 & 2369.6 & 736 & 271.00 & 199.5 \\
\hline I12 Hypertensive renal disease & 1159 & 1736.11 & 2012.2 & 254 & 1277.07 & 324.6 \\
\hline I50 Heart failure & 220,476 & 790.71 & $174,333.6$ & 19,892 & 776.83 & 15,453 \\
\hline I60 Subarachnoid haemorrhage & 9406 & 3339.63 & $31,412.6$ & 259 & 3129.97 & 810.4 \\
\hline I61 Intracerebral haemorrhage & 13,031 & 1555.16 & $20,265.3$ & 404 & 1507.63 & 608.6 \\
\hline $\begin{array}{l}\text { I62 Other non-traumatic intracranial } \\
\text { haemorrhage }\end{array}$ & 3736 & 2118.63 & 7915.2 & 113 & 2033.32 & 229.3 \\
\hline I63 Cerebral infarction & 15,523 & 909.46 & $14,117.5$ & 3787 & 920.99 & 3487.8 \\
\hline $\begin{array}{l}\text { I65 Occlusion and stenosis of precerebral } \\
\text { arteries, not resulting in cerebral infarction }\end{array}$ & 2775 & 2782.18 & 7720.5 & 115 & 2755.04 & 315.5 \\
\hline $\begin{array}{l}\text { I66 Occlusion and stenosis of cerebral } \\
\text { arteries, not resulting in cerebral infarction }\end{array}$ & 1255 & 840.22 & 1054.5 & 45 & 784.87 & 35.2 \\
\hline I67.2 Cerebral atherosclerosis & 49 & 1303.74 & 63.9 & 10 & 1313.46 & 12.9 \\
\hline I69 Sequelae of cerebrovascular disease & 7642 & 1577.12 & $12,052.4$ & 1096 & 1837.99 & 2014.7 \\
\hline $\begin{array}{l}\text { G45 Transient cerebral ischemic attacks } \\
\text { and related syndromes }\end{array}$ & 20,969 & 573.59 & $12,027.6$ & 4993 & 571.77 & 2854.6 \\
\hline Total cardiovascular disease * & 633,038 & 1404.17 & $888,894.5$ & 82,958 & 1529.05 & $126,847.9$ \\
\hline
\end{tabular}

* Numbers do not necessarily sum to totals because of rounding. 
Table 6. Number, average and total hospitalization cost due to renal, ophthalmological and neurological diseases, overall and related to diabetes microvascular complications, adults (20+ years), SUS, Brazil, 2014

\begin{tabular}{|c|c|c|c|c|c|c|}
\hline \multirow[b]{2}{*}{ Diabetes and Related Conditions } & \multicolumn{3}{|c|}{ Overall Hospitalization } & \multicolumn{3}{|c|}{ Hospitalization Due to Diabetes } \\
\hline & Number & $\begin{array}{c}\text { Average } \\
\text { Hospitalization Cost }\end{array}$ & $\begin{array}{c}\text { Total } \\
\text { Hospitalization Cost }\end{array}$ & Number & $\begin{array}{c}\text { Average } \\
\text { Hospitalization Cost }\end{array}$ & $\begin{array}{c}\text { Total } \\
\text { Hospitalization Cost }\end{array}$ \\
\hline & (n) & $(\operatorname{In} \$)$ & (in $000 \mathrm{Int} \$$ ) & (n) & $(\operatorname{Int} \$)$ & (in 000 Int\$) \\
\hline \multicolumn{7}{|l|}{ Renal diseases } \\
\hline N04 Nephrotic syndrome & 2156 & 362.89 & 782.4 & 313 & 379.81 & 119.1 \\
\hline R77.0 Abnormality of albumin & - & - & - & - & - & - \\
\hline R80 Isolated proteinuria & 2 & 72.08 & 144 & 0.2 & 74.58 & 15 \\
\hline N17 Acute renal failure & 21,960 & 1058.82 & $23,251.7$ & 5555 & 1030.23 & 5722.6 \\
\hline N18 Chronic kidney disease & 71,720 & 2243.99 & $160,939.2$ & 16,678 & 1816.06 & $30,288.3$ \\
\hline N19 Unspecified kidney failure & 48 & 162.37 & 7.8 & 13 & 102.91 & 1.3 \\
\hline Sub-total renal disease & 95,886 & 1929.18 & $184,981.3$ & 22,559 & 1601.63 & $36,131.2$ \\
\hline \multicolumn{7}{|l|}{ Eye diseases } \\
\hline H25 Senile cataract & 37,852 & 343.59 & $13,005.7$ & 15,947 & 342.19 & 5456.9 \\
\hline H28 Cataract and other disorders of lens in diseases classified elsewhere & 46 & 289.47 & 13.3 & 17 & 277.92 & 4.6 \\
\hline H33 Retinal detachments and breaks & 15,858 & 1560.10 & $24,740.1$ & 4773 & 1560.32 & 7447.01 \\
\hline H34 Retinal vascular occlusions & 8 & 55.06 & 440 & 3 & 52.36 & 143 \\
\hline H35.0 Background retinopathy and retinal vascular changes & 5 & 105.61 & 528 & 2 & 41.76 & 80 \\
\hline H35.2 Other proliferative retinopathy & - & - & - & - & - & - \\
\hline H36.0 Retinal disorders in diseases classified elsewhere & 159 & 128.45 & 20.4 & 53 & 129.84 & 6.9 \\
\hline H42 Glaucoma in diseases classified elsewhere & 21 & 305.80 & 6.4 & 6 & 313.53 & 1.8 \\
\hline H54 Visual impairment including blindness (binocular or monocular) & 56 & 837.97 & 46.9 & 14 & 968.52 & 13.5 \\
\hline Sub-total ophthalmological disease & 54,005 & 700.56 & $37,833.9$ & 20,814 & 621.26 & $12,931.1$ \\
\hline \multicolumn{7}{|l|}{ Neurological diseases } \\
\hline G90 Disorders of autonomic nervous system & 205 & 1347.22 & 276.9 & 23 & 1821.26 & 41.5 \\
\hline G56 Mononeuropathies of upper limb & 13,303 & 251.55 & 3346.3 & 1678 & 250.63 & 420.5 \\
\hline G57 Mononeuropathies of lower limb & 223 & 522.86 & 116.6 & 24 & 585.04 & 14,3 \\
\hline G59.0 Diabetic mononeuropathy & 5 & 163.55 & 818 & 1 & 174.99 & 169 \\
\hline G63 Polyneuropathy in diseases classified elsewhere & 2407 & 355.05 & 854.6 & 334 & 347.54 & 116.1 \\
\hline G52 Disorders of other cranial nerves & 239 & 1319.55 & 315.4 & 30 & 1253.71 & 37.4 \\
\hline L97 Ulcer of lower limb, not elsewhere classified & 30,145 & 527.87 & $15,912.6$ & 4673 & 534.64 & 2498.4 \\
\hline S88 Traumatic amputation of lower leg & 1031 & 1040.48 & 1072.7 & 638 & 1023.73 & 653.1 \\
\hline S98 Traumatic amputation of ankle and foot & 2586 & 397.03 & 1026.7 & 984 & 455.94 & 448.8 \\
\hline R02 Gangrene, not elsewhere classified & 25,564 & 678.54 & $17,346.1$ & 13,107 & 730.75 & 9577.8 \\
\hline M86 Osteomyelitis & 13,209 & 572.71 & 7564.9 & 4480 & 625.41 & 2801.8 \\
\hline M87 Osteonecrosis & 1785 & 1859.59 & 3319.4 & 736 & 2064.04 & 1520.01 \\
\hline Sub-total neurological disease & 90,702 & 563.96 & $51,152.3$ & 26,708 & 678.80 & $18,129.3$ \\
\hline Total renal, ophthalmological and neurological disease * & 240,593 & 1138.72 & $273,967.4$ & 70,081 & 958.77 & $67,191.6$ \\
\hline
\end{tabular}

* Numbers do not necessarily sum to totals because of rounding. 
Table 7. Number, average and total hospitalization cost due to respiratory and urinary infectious diseases, overall and related to diabetes, adults (20+ years), SUS, Brazil 2014.

\begin{tabular}{|c|c|c|c|c|c|c|}
\hline \multirow[b]{2}{*}{ Diabetes and Related Conditions } & \multicolumn{3}{|c|}{ Overall Hospitalization } & \multicolumn{3}{|c|}{ Hospitalization Due to Diabetes } \\
\hline & Number & $\begin{array}{c}\text { Average } \\
\text { Hospitalization Cost }\end{array}$ & $\begin{array}{c}\text { Total } \\
\text { Hospitalization Cost }\end{array}$ & Number & $\begin{array}{c}\text { Average } \\
\text { Hospitalization Cost }\end{array}$ & $\begin{array}{c}\text { Total } \\
\text { Hospitalization Cost }\end{array}$ \\
\hline & (n) & $($ Int\$) & (in 000 Int\$) & (n) & $($ Int\$) & (in 000 Int\$) \\
\hline \multicolumn{7}{|l|}{ Respiratory infections } \\
\hline J12 Viral pneumonia, not elsewhere classified & 22,596 & 499.97 & $11,297.3$ & 1075 & 530.04 & 569.9 \\
\hline J13 Pneumonia due to Streptococcus pneumoniae & 1315 & 508.58 & 668.8 & 76 & 520.54 & 39.6 \\
\hline J14 Pneumonia due to Haemophilus influenzae & 288 & 435.05 & 125.3 & 13 & 422.61 & 5.7 \\
\hline J15 Bacterial pneumonia, not elsewhere classified & 79,130 & 679.63 & $53,778.8$ & 4250 & 712.67 & 3028.8 \\
\hline Sub-total lower respiratory tract infections & 358,220 & 619.06 & $221,760.1$ & 19,661 & 637.67 & $12,537.1$ \\
\hline \multicolumn{7}{|l|}{ Urinary tract infections } \\
\hline N10 Acute tubulo-interstitial nephritis & 20,247 & 200.30 & 4055.5 & 472 & 232.49 & 109.7 \\
\hline N15.1 Renal and perinephric abscess & 699 & 1040.41 & 727.2 & 17 & 1071.13 & 18.1 \\
\hline N30.0 Acute cystitis & 6873 & 217.55 & 1495.2 & 180 & 257.28 & 46.3 \\
\hline N30.8 Other cystitis & 1718 & 215.64 & 370.5 & 44 & 237.58 & 10.4 \\
\hline Sub-total urinary tract infections & 29,537 & 225.09 & 6648.5 & 712 & 258.93 & 184.5 \\
\hline Total infectious disease * & 387,757 & 589.05 & $228,408.6$ & 20,373 & 624.43 & $12,721.6$ \\
\hline
\end{tabular}


Table 8. Number, average and total hospitalization cost due to neoplasms, overall and related to diabetes, adults (20+ years), SUS, Brazil, 2014.

\begin{tabular}{|c|c|c|c|c|c|c|}
\hline \multirow[b]{2}{*}{ Diabetes and Related Conditions } & \multicolumn{3}{|c|}{ Overall Hospitalization } & \multicolumn{3}{|c|}{ Hospitalization Due to Diabetes } \\
\hline & Number & $\begin{array}{c}\text { Average } \\
\text { Hospitalization Cost }\end{array}$ & $\begin{array}{c}\text { Total } \\
\text { Hospitalization Cost }\end{array}$ & Number & $\begin{array}{c}\text { Average } \\
\text { Hospitalization Cost }\end{array}$ & $\begin{array}{c}\text { Total } \\
\text { Hospitalization Cost }\end{array}$ \\
\hline & (n) & (Int\$) & (in 000 Int\$) & (n) & (Int\$) & (in 000 Int\$) \\
\hline \multicolumn{7}{|l|}{ Breast } \\
\hline C50 Malignant neoplasm of breast & 55,580 & 1160.08 & $64,477.2$ & 2200 & 1146.46 & 2522.2 \\
\hline D05.9 Carcinoma in situ of breast, unspecified & 1192 & 989.73 & 1179.8 & 44 & 999.72 & 43.5 \\
\hline Sub-total breast cancer & 56,772 & 1156.50 & $65,656.9$ & 2244 & 1143.61 & 2565.7 \\
\hline \multicolumn{7}{|l|}{ Endometrium } \\
\hline C54.1 Malignant neoplasm of corpus uteri & 3539 & 1409.76 & 4989.1 & 716 & 1429.85 & 1023.4 \\
\hline $\begin{array}{l}\text { D07.0 Carcinoma in situ of other and unspecified } \\
\text { genital organs }\end{array}$ & 202 & 151.49 & 30.6 & 31 & 158.36 & 4.9 \\
\hline Sub-total endometrium cancer & 3741 & 1341.82 & 5019.7 & 747 & 1376.34 & 1028.4 \\
\hline \multicolumn{7}{|l|}{ Pancreas } \\
\hline C25 Malignant neoplasm of pancreas & 7867 & 1173.41 & 9231.2 & 1464 & 1128.19 & 1652.2 \\
\hline Sub-total pancreas cancer & 7867 & 1173.41 & 9231.2 & 1464 & 1128.19 & 1652.2 \\
\hline \multicolumn{7}{|l|}{ Liver and intrahepatic bile ducts } \\
\hline C22.1 Intrahepatic bile duct carcinoma & 807 & 1082.93 & 873.9 & 151 & 1069.35 & 161.9 \\
\hline C22.0 Liver cell carcinoma & 2517 & 1306.91 & 3289.5 & 589 & 1282.92 & 755.4 \\
\hline C22.7 Other specified carcinomas of liver & 882 & 1545.40 & 1363.0 & 197 & 1455.41 & 287.1 \\
\hline $\begin{array}{l}\text { C22.9 Malignant neoplasm of liver and intrahepatic } \\
\text { bile ducts-liver, unspecified }\end{array}$ & 3158 & 547.64 & 1729.4 & 726 & 527.42 & 383.2 \\
\hline Sub-total liver and cholangiocarcinoma cancer & 7364 & 985.32 & 7255.9 & 1664 & 954.10 & 1587.6 \\
\hline \multicolumn{7}{|l|}{ Colorectal } \\
\hline C18 Malignant neoplasm of colon & 37,627 & 1238.60 & $46,604.8$ & 2187 & 1329.29 & 2907.7 \\
\hline C19 Malignant neoplasm of recto sigmoid junction & 2946 & 2727.89 & 8036.4 & 181 & 2787.70 & 505.01 \\
\hline Sub-total colorectal cancer & 40,573 & 1346.74 & $54,641.2$ & 2369 & 1440.83 & 3412.7 \\
\hline Total neoplasms disease * & 116,317 & 1219.13 & $141,804.9$ & 8488 & 1207.23 & $10,246.6$ \\
\hline
\end{tabular}

${ }^{*}$ Numbers do not necessarily sum to totals because of rounding. 


\section{Discussion}

Brazil is one of the most populated countries in the world, with an estimated population of 137.6 million adults in 2014 [31]. Based on recent prevalence estimates, we have estimated that 17.3 million individuals aged 20 years and older had diabetes in Brazil (Supplementary Table S2). Despite increasing trends in diabetes prevalence in the country, mortality due to diabetes declined $1.7 \%$ per year (from 40.6/100 thousand population to 33.7/100 thousand population) from 2000 to 2011, probably as a result of better access to healthcare, thus reducing mortality due to acute events [32]. However, when diabetes was analyzed as an associated cause of death due to other causes, there was an increase of $8 \%$ between 2000 and 2007 [33], most likely representing deaths due to chronic diabetes complications and related conditions.

Hospitalizations represent an important part of the consumption of health resources in different health systems and countries around the world and patients with type 2 diabetes had higher rates of hospitalization than the general population [34]. In the United States in 2012, diabetes hospitalization costs were the most significant cost component ( $43 \%$ ) of direct medical costs ( $\$ 176$ billion) associated with diabetes, which added to $\$ 245$ billion when considering both direct and indirect costs [25].

The estimated costs of hospitalizations due to diabetes and related conditions estimated in this study (Int $\$ 264.9$ million) represent $4.6 \%$ of all hospitalizations and $0.45 \%$ of all expenditures for actions and public services of health provided by the Ministry of Health in 2014 (Int $\$ 58.3$ billion) [35]. In this same year, total health expenditures in Brazil were $8 \%$ of its Gross Domestic Product of which $46 \%$ was associated with public health expenditures (Int $\$ 606$ per capita) [36]. This spending is equivalent to Int $\$ 1.92$ per adult by the federal government only with hospitalizations for DM and its complications. The average value of an adult hospitalization due to diabetes was 19\% higher than a hospitalization without diabetes, and hospitalizations due to kidney and cardiovascular diseases were the ones with higher average cost.

Most countries in Latin America have adopted public health systems with universal coverage in the last few decades. Nonetheless, disparities in per capita government health expenditure can be observed in the region [37] and a wide difference can be identified between countries that share historic similarities, with Venezuela with the lowest (Int\$270.88), and Cuba (Int\$2366.06) the highest per capita government health expenditure [36]. When contrasting with high-income developed countries in other regions, disparities are more pronounced, with United States (Int\$4541.17), United Kingdom (Int\$2807.62), and Japan (Int\$3115.08) among the highest per capita expenditures [36].

Our results demonstrated that the population aged 65 years and older used a much larger portion of hospital resources, both in number of hospitalization and costs, similar to results demonstrated in the United States in 2012 [25]. Cardiovascular complications attributable to diabetes also represented the largest share of all hospitalizations, both in number of hospitalizations and costs.

Although when considering crude rates, women were more likely to be hospitalized than men, when adjusting for age taking into consideration the different age structure between men and women, men are more likely to be hospitalized than women. Although men had relatively higher hospitalization costs than women from age group 20-74 years, except for the $\geq 75$ years age group, this may be due to the relatively longer life expectancy in women, compared with men [38]. Hospitalizations reported as having diabetes as the main diagnosis were the most frequent $(41.9 \%)$, although with lower costs. They currently represent a small proportion of all hospitalization expenses for the Brazilian National Health System, but are expected to increase considerably as the population ages. Moreover, hospitalization costs related to diabetes, but not captured by a first listed diabetes diagnosis, must be integrated with these costs to give a more comprehensive picture of the overall disease burden attributable to diabetes.

The total number of hospitalizations due to DM-related conditions was 2.4 times that of hospitalizations for first-listed DM; however, spending was almost 5.5 times higher. Microvascular diseases due to diabetes (kidney, eye and neurologic diseases) accounted for a greater share of total hospitalizations $(29.1 \%)$ and associated costs $(24.5 \%)$, part of which could be prevented with a better 
metabolic control. These results were in accordance with others that show hospitalizations for diabetes complications had a higher average cost than those for diabetes itself $[25,39,40]$.

The hospitalization costs due to infectious diseases and selected neoplasms in adults with DM were $4.8 \%$ and $3.9 \%$, respectively, of the total hospitalizations due to DM. Although it represents a small percentage compared with vascular diseases, currently, this was the first Brazilian study to consider DM as an important contributor to such hospitalizations and costs.

Comparisons with Brazilian studies for 1999-2001 [41] and 2008-2010 [42], that used the same attributable risk methodology to estimate hospitalizations for DM in the Brazilian public network, should be performed with caution. In both previous studies, the results encompassed all age groups while in the current, only adults. In addition, in the two previous studies, hospitalizations were also estimated for the general medical conditions group, i.e., all other ICD-10 diseases that are not attributed to diabetes or its complications but for which individuals with DM were hospitalized more frequently. In contrast, in the current study, some of these conditions, such as certain neoplasms and lower respiratory and urinary tract infections, were computed as diabetes complications. It is also recognizable that the more recent literature has brought lower relative risks from international studies for the calculation of etiological fractions, although it was partially offset by the double of self-reported prevalence.

Our study has several limitations which are worth noting. The source of the data (SIH/SUS) was initially developed for administrative-financial functions for the purpose of collection and may not be free of coding errors, intentional or not. This is reflected by the high number of individuals hospitalized for whom the main diagnosis reported as DM was "unspecified DM-E14" ( $n=68,987)$, and "insulin-dependent hospitalizations-E10" $(\mathrm{n}=38,883)$, significantly higher than those reported as "non-insulin dependent diabetes-E11" $(12,707)$. We believe that most of these cases reported as E14 are indeed individuals with type $2 \mathrm{DM}$. Also, many of the cases reported as E10 may be individuals with type 2 diabetes using insulin.

In addition, the SUS covers $75 \%$ of the population in Brazil, which means about one quarter of population with diabetes was not included in the data analysis, and thus our estimates may be underestimated. Moreover, the diabetes hospitalization rates may be different among those not covered by SUS. As SIH data do not incorporate critical variables with explanatory potential, such as body mass index, race, schooling, severity of the clinical condition at the time of hospitalization, degree of use of the services, readmissions and other, we are not able to identify the role of these possible factors in diabetes hospitalizations.

Another limitation is we considered only the adult population, as the focus of the study was on type $2 \mathrm{DM}$, which is more amenable to prevention strategies. As such, although hospitalizations due to type 1 DM may have been inadvertently included in our estimation, on the other hand, we might have underestimated cases of type $2 \mathrm{DM}$ in those younger than 20 years of age.

Finally, as the more recent prevalence estimate available was that for self-reported diabetes [5], to account for undiagnosed diabetes, and as done by other authors [21], we applied a factor of 2, considering high quality recent evidence from Brazil [7]. The resulting diabetes prevalence of $12.4 \%$ considered in our analyses is consistent with sub-national studies in Brazil which a decade ago showed 2 digit prevalence figures in selected regions of the country, being $12.1 \%$ in the city of Ribeirão Preto [43], $12.4 \%$ in Porto Alegre [44], and 13.5\% in São Carlos [45]. It is also consistent with prevalence estimates considered for global disease burden estimate studies [21].

\section{Conclusions}

This study presented a detailed overview of the hospitalizations attributable to DM in the Brazilian public network. It is a study that deals with the epidemiological and economic aspects of the public expenses with a disease. They portrayed an "epidemiological iceberg" present in developing societies such as Brazil. By increasing the incidence and severity of other diseases, diabetes increases the chances of hospitalization of patients and the use of more aggressive therapies. We believe that improving 
the quality of life of these patients depends, among other measures, on the expansion of preventive activities in order to reduce the need for hospitalization, minimize complications and reduce the severity of other more general medical conditions. Our estimate is part of the monitoring and analysis of the health situation for the necessary interventions. Understanding the costs of diabetes and its major complications is crucial to raise awareness and allow the assessment of strategies to reduce its prevalence and their impact.

Supplementary Materials: The following are available online at www.mdpi.com/1660-4601/15/2/294/s1, Table S1: DM and related conditions and relative risks, Table S2: State level prevalence and hospitalization cost due to diabetes and related conditions, adults (20+ years), SUS, Brazil, 2014.

Acknowledgments: This study was funded by the Brazilian Ministry of Health through the National Health Fund (Process \# 25000.105417/2014-01), as part of a larger study to estimate the costs of type 2 diabetes mellitus in Brazil. The Brazilian Institute of Health Technology (IATS)/National Council for Scientific and Technological Development (CNPq) supported the open access publication costs.

Author Contributions: M.Q.M.R., R.S.R., L.R.B., D.V.A., C.M.T. conceived and designed the experiments; M.Q.M.R., R.S.R., D.V.A., L.R.B., C.M.T. performed the experiments; M.Q.M.R., R.S.R., M.G.C., D.V.A., L.R.B., C.M.T. analyzed the data; M.Q.M.R., R.S.R., M.G.C., D.V.A., L.R.B., C.M.T. contributed materials/analysis tools; M.Q.M.R., R.S.R., D.V.A., L.R.B., C.M.T. wrote the paper.

Conflicts of Interest: The authors declare no conflict of interest. The founding sponsors had no role in the design of the study; in the collection, analyses, or interpretation of data; in the writing of the manuscript, and in the decision to publish the results.

\section{References}

1. World Health Organization. Deaths from Ncds. Available online: http://www.who.int/gho/ncd/mortality morbidity/ncd_total/en/ (accessed on 20 April 2017).

2. World Health Organization. Global Status Report on Noncommunicable Diseases 2014; 2015-10-05 03:00:00; World Health Organization: Geneva Switzerland, 2015.

3. International Diabetes Federation. IDF Diabetes Atlas, 7th Edition. Available online: http://www. diabetesatlas.org/resources/2017-atlas.html (accessed on 11 April 2017).

4. Worldwide trends in diabetes since 1980: A pooled analysis of 751 population-based studies with 4.4 million participants. Lancet 2017, 387, 1513-1530.

5. Instituto Brasileiro de Geografia e Estatística (IBGE). Pesquisa Nacional de Saúde-2013: Percepção do Estado de Saúde, Estilos de Vida e Doenças Crônicas: Brasil, Grandes Regiões e Unidades da Federação; IBGE: Rio de Janeiro, Brazil, 2014.

6. Malerbi, D.A.; Franco, L.J. Multicenter study of the prevalence of diabetes mellitus and impaired glucose tolerance in the urban brazilian population aged 30-69 years. The brazilian cooperative group on the study of diabetes prevalence. Diabetes Care 1992, 15, 1509-1516. [CrossRef] [PubMed]

7. Schmidt, M.I.; Hoffmann, J.F.; Diniz, M.D.F.S.; Lotufo, P.A.; Griep, R.H.; Bensenor, I.M.; Mill, J.G.; Barreto, S.M.; Aquino, E.M.L.; Duncan, B.B. High prevalence of diabetes and intermediate hyperglycemia-The brazilian longitudinal study of adult health (elsa-brasil). Diabetol. Metab. Syndr. 2014, 6, 123. [CrossRef] [PubMed]

8. Kim, S.; Boye, K.S. Excessive hospitalizations and its associated economic burden among people with diabetes in the united states. Value Health 2009, 12, 267-272. [CrossRef] [PubMed]

9. Chen, D.; Liu, S.; Tan, X.; Zhao, Q. Assessment of hospital length of stay and direct costs of type 2 diabetes in hubei province, china. BMC Health Serv. Res. 2017, 17, 199. [CrossRef] [PubMed]

10. Donnan, P.T.; Leese, G.P.; Morris, A.D. Hospitalizations for people with type 1 and type 2 diabetes compared with the nondiabetic population of tayside, scotland: A retrospective cohort study of resource use. Diabetes Care 2000, 23, 1774-1779. [CrossRef] [PubMed]

11. Khalid, J.M.; Raluy-Callado, M.; Curtis, B.H.; Boye, K.S.; Maguire, A.; Reaney, M. Rates and risk of hospitalisation among patients with type 2 diabetes: Retrospective cohort study using the uk general practice research database linked to english hospital episode statistics. Int. J. Clin. Pract. 2014, 68, 40-48. [CrossRef] [PubMed] 
12. Rubin, D.J. Hospital readmission of patients with diabetes. Curr. Diabetes Rep. 2015, 15, 17. [CrossRef] [PubMed]

13. Enomoto, L.M.; Shrestha, D.P.; Rosenthal, M.B.; Hollenbeak, C.S.; Gabbay, R.A. Risk factors associated with 30-day readmission and length of stay in patients with type 2 diabetes. J. Diabetes Complicat. 2017, 31, 122-127. [CrossRef] [PubMed]

14. World Health Organization. Diabetes. Fact Sheet. Available online: http://www.who.int/mediacentre/ factsheets/fs312/en/ (accessed on 7 October 2017).

15. Ministério da Saúde, Secretaria de Políticas Públicas. Plano de reorganização da atenção à hipertensão arterial e ao diabetes mellitus. Rev. Saude Publica 2001, 35, 585-588.

16. Toscano, C.M.; Duncan, B.B.; Mengue, S.S.; Polanczyk, C.A.; Nucci, L.B.; Forti, A.C.E.; Fonseca, C.D.; Schmidt, M.I. Initial impact and cost of a nationwide population screening campaign for diabetes in Brazil: A follow up study. BMC Health Serv. Res. 2008, 8, 189. [CrossRef] [PubMed]

17. Toscano, C.M.; Zhuo, X.; Imai, K.; Duncan, B.B.; Polanczyk, C.A.; Zhang, P.; Engelgau, M.; Schmidt, M.I. Cost-effectiveness of a national population-based screening program for type 2 diabetes: The Brazil experience. Diabetol. Metab. Syndr. 2015, 7, 95. [CrossRef] [PubMed]

18. Ministério da Saúde, Secretaria de Vigilância em Saúde. Departamento de Análise de Situação de Saúde. Plano de Ações Estratégicas Para o Enfrentamento das Doenças Crônicas não Transmissíveis (dcnt) no Brasil 2011-2022; Ministério da Saúde, Secretaria de Vigilância em Saúde: Brasília, Brazil, 2011.

19. Brasil Ministério da Saúde. Beneficiary Information System. Available online: http://tabnet.datasus.gov.br/ cgi/tabcgi.exe?idb2012/f16.def (accessed on 20 April 2017).

20. Okura, Y.; Urban, L.H.; Mahoney, D.W.; Jacobsen, S.J.; Rodeheffer, R.J. Agreement between self-report questionnaires and medical record data was substantial for diabetes, hypertension, myocardial infarction and stroke but not for heart failure. J. Clin. Epidemiol. 2004, 57, 1096-1103. [CrossRef] [PubMed]

21. Shaw, J.E.; Sicree, R.A.; Zimmet, P.Z. Global estimates of the prevalence of diabetes for 2010 and 2030. Diabetes Res. Clin. Pract. 2010, 87, 4-14. [CrossRef] [PubMed]

22. Ministério da Saúde. Datasus. File Transfer Service. Available online: http://www2.datasus.gov.br/ DATASUS /index.php?area=0901\&item $=1 \&$ acao=25 (accessed on 25 October 2016).

23. World Health Organization. International Classification of Diseases (icd) 10. Available online: http:/ / apps. who.int/classifications/icd10/browse/2016/en (accessed on 20 June 2017).

24. Instituto Brasileiro de Geografia e Estatística (IBGE). Census. Available online: http:/ / downloads.ibge.gov. br/downloads_estatisticas.htm (accessed on 20 June 2017).

25. American Diabetes Association. Economic costs of diabetes in the U.S. In 2012. Diabetes Care 2013, 36, 1033-1046.

26. Pagano, E.; Brunetti, M.; Tediosi, F.; Garattini, L. Costs of diabetes. A methodological analysis of the literature. Pharmacoeconomics 1999, 15, 583-595. [CrossRef] [PubMed]

27. American Diabetes Association. Economic consequences of diabetes mellitus in the U.S. In 1997. American diabetes association. Diabetes Care 1998, 21, 296-309.

28. Dawson, K.G.; Gomes, D.; Gerstein, H.; Blanchard, J.F.; Kahler, K.H. The economic cost of diabetes in Canada, 1998. Diabetes Care 2002, 25, 1303-1307. [CrossRef] [PubMed]

29. Ministério da Saúde. System of Management of the Table of Procedures, Medications and Opm from Sus. Available online: http://sigtap.datasus.gov.br/tabela-unificada/app/sec/inicio.jsp (accessed on 18 April 2017).

30. World Bank. PPP Conversion Factor, GDP (LCU per International \$). Available online: https://data. worldbank.org/indicator/PA.NUS.PPP (accessed on 18 April 2017).

31. Instituto Brasileiro de Geografia e Estatística; Sistema IBGE de Recuperação Automática. Pesquisa Nacional por Amostra de Domicílios de 2001 a 2015. Available online: https://sidra.ibge.gov.br/pesquisa/pnad (accessed on 11 April 2017).

32. Malta, D.C.; Moura, L.D.; Prado, R.R.D.; Escalante, J.C.; Schmidt, M.I.; Duncan, B.B. Mortalidade por doenças crônicas não transmissíveis no brasil e suas regiões, 2000 to 2011. Epidemiol. Serv. Saúde 2014, 23, 599-608. [CrossRef]

33. Schmidt, M.I.; Duncan, B.B.; Silva, G.A.E.; Menezes, A.M.; Monteiro, C.A.; Barreto, S.M.; Chor, D.; Menezes, P.R. Chronic non-communicable diseases in Brazil: Burden and current challenges. Lancet 2011, 377, 1949-1961. [CrossRef] 
34. Bo, S.; Ciccone, G.; Grassi, G.; Gancia, R.; Rosato, R.; Merletti, F.; Pagano, G.F. Patients with type 2 diabetes had higher rates of hospitalization than the general population. J. Clin. Epidemiol. 2004, 57, 1196-1201. [CrossRef] [PubMed]

35. Presidência da República Brasil. Prestação de Contas da Presidenta da República-2014. Available online: http://www.cgu.gov.br/assuntos/auditoria-e-fiscalizacao/avaliacao-da-gestao-dosadministradores / prestacao-de-contas-do-presidente-da-republica/arquivos/2014/pcpr2014.pdf (accessed on 15 October 2017).

36. World Health Organization. Global Health Observatory Data Repository. Health Financing. Available online: http:/ / apps.who.int/gho/data/node.main.484 (accessed on 15 October 2017).

37. Atun, R.; de Andrade, L.O.; Almeida, G.; Cotlear, D.; Dmytraczenko, T.; Frenz, P.; Garcia, P.; Gomez-Dantes, O.; Knaul, F.M.; Muntaner, C.; et al. Health-system reform and universal health coverage in latin america. Lancet 2015, 385, 1230-1247. [CrossRef]

38. Instituto Brasileiro de Geografia e Estatística (IBGE). Tábua Completa de Mortalidade Para o Brasil-2014. Breve Análise da Evolução da Mortalidade no Brasil. Available online: ftp://ftp.ibge.gov.br/Tabuas_ Completas_de_Mortalidade/Tabuas_Completas_de_Mortalidade_2014/notastecnicas.pdf (accessed on 17 January 2018).

39. American Diabetes Association. Economic costs of diabetes in the U.S. In 2002. Diabetes Care 2003, 26, 917-932.

40. American Diabetes Association. Economic costs of diabetes in the U.S. In 2007. Diabetes Care 2008, 31, 596-615.

41. Rosa, R.D.S.; Schmidt, M.I. Diabetes mellitus: Magnitude das hospitalizações na rede pública do brasil, 1999-2001. Epidemiol. Serv. Saude 2008, 17, 131-134. [CrossRef]

42. Rosa, R.; Nita, M.E.; Rached, R.; Donato, B.; Rahal, E. Estimated hospitalizations attributable to diabetes mellitus within the public healthcare system in Brazil from 2008 to 2010: Study diaps 79. Rev. Assoc. Med. Bras. 2014, 60, 222-230. [CrossRef] [PubMed]

43. Torquato, M.T.; Montenegro Junior, R.M.; Viana, L.A.; de Souza, R.A.; Lanna, C.M.; Lucas, J.C.; Bidurin, C.; Foss, M.C. Prevalence of diabetes mellitus and impaired glucose tolerance in the urban population aged 30-69 years in Ribeirao Preto (Sao Paulo), Brazil. Sao Paulo Med. J. 2003, 121, 224-230. [CrossRef] [PubMed]

44. Schaan, B.D.; Harzheim, E.; Gus, I. Cardiac risk profile in diabetes mellitus and impaired fasting glucose. Rev. Saude Publica 2004, 38, 529-536. [CrossRef] [PubMed]

45. Bosi, P.L.; Carvalho, A.M.; Contrera, D.; Casale, G.; Pereira, M.A.; Gronner, M.F.; Diogo, T.M.; Torquarto, M.T.; Oishi, J.; Leal, A.M. Prevalence of diabetes and impaired glucose tolerance in the urban population of 30 to 79 years of the city of sao carlos, sao paulo. Arq. Bra. Endocrinol. Metabol. 2009, 53, 726-732. [CrossRef] 